\title{
On the Behavior of Newly Synthesized Functionalized Imidazolium-Based Ionic Liquids for Highly Efficient Extraction and Separation of Pirimicarb from Orchard Real Wastewater
}

\author{
Sana Zulfiqar $\mathbb{D}^{1},{ }^{1}$ Uzaira Rafique, ${ }^{1}$ M. Javed Akhtar, ${ }^{2}$ and Hesham Hamad $\mathbb{D}^{3}$ \\ ${ }^{1}$ Department of Environmental Sciences, Fatima Jinnah Women University, Rawalpindi, Pakistan \\ ${ }^{2}$ Pakistan Institute of Nuclear Science and Technology, Nilore, Pakistan \\ ${ }^{3}$ Fabrication Technology Research Department, Advanced Technology and New Materials Research Institute (ATNMRI), City of \\ Scientific Research and Technological Applications (SRTA-City), Alexandria 21934, Egypt
}

Correspondence should be addressed to Sana Zulfiqar; sanazulfiqar@fjwu.edu.pk and Hesham Hamad; hhamad@chem.uw.edu.pl

Received 8 December 2021; Revised 12 January 2022; Accepted 13 January 2022; Published 17 February 2022

Academic Editor: Tony Hadibarata

Copyright (C) 2022 Sana Zulfiqar et al. This is an open access article distributed under the Creative Commons Attribution License, which permits unrestricted use, distribution, and reproduction in any medium, provided the original work is properly cited.

The presence of pirimicarb compounds as pollutants in orchard wastewater has sparked rising worries about their detrimental impacts on the ecosystem and human health, and their removal is critical for Pakistan's aquatic environment. It not only contaminates fruit, but it also leaches into the soil and contaminates groundwater. However, there is little data on the effective removal of pirimicarb from orchard wastewater. The main purpose of this study is to create a novel family of functionalized imidazolium-based ionic liquids (ILs) using a simple chemical process, which will be utilized for the first time to extract pirimicarb from orchard wastewater in an efficient, cost-effective, and environmentally acceptable manner. FTIR, SEM, XRD, TGA, BET, and ${ }^{1} \mathrm{H}$ NMR spectroscopy were used to characterize the functionalized samples. The impact of the IL substituent on the separation capacity was studied. In addition, the extraction and separation of pirimicarb from orchard wastewater were investigated under a variety of conditions (time, concentration, and temperature) in order to better understand the adsorption behaviors of distinct ILs in an aqueous solution. The adsorption equilibrium was reached in 30 minutes, and the maximum removal of pirimicarb was achieved utilizing the synthesized $\left[\mathrm{C}_{2} \mathrm{im}\right]\left[\mathrm{C}_{3} \mathrm{H}_{6} \mathrm{NH}_{2}\right] \mathrm{Br}^{-}$, according to the data. The pseudo-firstorder model and the Langmuir model both suit well with the adsorption mechanism of pirimicarb with very good adsorptive capacities. Thermodynamic analyses indicated spontaneous, endothermic, and entropy-driven adsorption processes. The synthesized imidazolium-based ILs have good regeneration capability and recycling at least for six adsorption-desorption runs and have also been used to successfully detect pirimicarb orchard wastewater samples. The superior safety of the proposed method nominates it as a promising future strategy for pollution prevention. Consequently, this work has proven that the pirimicarb adsorption to various imidazolium-based ILs was dependent on the structures of the produced imidazolium-based ILs, which specifies its potential for practical applications in water pollutant removal and environmental remediation.

\section{Introduction}

The use of pesticides is critical for the management of pests and insect-borne diseases, which leads to an increased food supply. Although pesticides are beneficial to agriculture, their rising use has had a negative impact on humans and the environment as a whole. Because of its low persistence and great efficacy, the carbamate pesticide family has been widely used in the pest control of vegetable crops. The US
Environmental Protection Agency (EPA) considers carbamate herbicide to be one of the most harmful contaminants in the environment $[1,2]$. Because it is highly soluble in aqueous mediums and circulates into surface and groundwater through soil leaks, this family is poisonous and poses a threat to all living species [3].

In particular, pirimicarb (2-dimethylamino-5,6dimethylpyrimidin-4-yldimethylcarbamate) is an important substituted N, N-dimethylcarbamate insecticide, and it has 
been widely employed against aphids in fruit and vegetable $[1,4]$. Pirimicarb has been classified as moderately hazardous (Class II) by the World Health Organization (WHO) because it has low toxicity, is potentially carcinogenic and mutagenic in mammals, and poses a threat to living organisms due to its inhibition of the enzyme acetylcholinesterase $[3,5,6]$. Pirimicarb is sprayed into the ground and surface water without being treated before being discharged into the streams. To protect human health, hydrolytic resources, and the aquatic environment, it is critical to investigate simple, inexpensive, and effective strategies for removing pirimicarb from water.

These strategies can be replaced by new alternate technologies for the removal of organic pollutants from wastewater such as biological treatment [7], electrochemical treatment [8], photocatalytic degradation [9], membrane separation process [10], and adsorption [11]. Among them, adsorption is a very efficient, greener, and cost-effective process for wastewater treatment [12]. Various adsorbents, zeolites, nanoparticles, carbon nanotubes, and metal-organic frameworks have been prepared and synthesized to detoxify/decontaminate wastewater by removing persistent organic pollutants (POPs) [13].

Ionic liquids (ILs) have been used as a solvent medium in different chemical reactions for environmental remediation, but very few scientists considered them for the adsorption process so far. The use of ILs as adsorbents possesses various advantages, i.e., ILs with any aromatic functional group are used for the removal of polyaromatic hydrocarbons (PAHs) from the environment while ILs that have amine as a functional group efficiently are used for toxic gases adsorptions, e.g., $\mathrm{CO}_{2}, \mathrm{NO}_{2}$, and $\mathrm{SO}_{2}$.

ILs have also recently received a lot of attention for their green chemistry and clean processes and as functional inorganic materials for a variety of applications in various fields [14]. It has structural and chemical characteristics that distinguish it from other functional materials, including low vapor pressure, nonvolatility, nonflammability, noncorrosive, variable viscosities, adjustable miscibility, reusability, higher conductivity, and very high chemical and thermal stability $[15,16]$. Because of their high stability, they could be long-term and high-efficiency materials in an environmental application.

At temperatures below $100^{\circ} \mathrm{C}$, the strong coulumbic attraction between strong inorganic anions and asymmetric organic cations can be expressively changed to improve the physicochemical properties of ILs such as solvent selection, hydrophobicity, melting point, and viscosity $[17,18]$. The modified ILs can perform exceptionally well in terms of separation. For example, cellulose acetate imidazolium-based ILs were utilized to extract pirimicarb from real wastewater, with a $74 \%$ removal efficiency under ideal conditions [19]. Similarly, researchers used ionic liquids for the removal of contaminants from water. According to the results, ILs were proved as a good alternative material option used for contaminants analysis in water as compared to solid-phase extraction materials due to their universality in liquid media and in an atmospheric environment [20].
The present study is conducted using eco-friendly, lowcost reactants to synthesize greener electrolytes "ionic liquids" in order to perform its real-world application. To the best of our knowledge, there is no comparative study for the carbamate removal from orchard wastewater using different types of imidazolium-based ILs ([im] $\left[\mathrm{C}_{3} \mathrm{H}_{6} \mathrm{NH}_{2}\right] \mathrm{Br}$-, $\left.[\mathrm{im}]\left[\mathrm{C}_{3} \mathrm{H}_{6} \mathrm{NH}_{2}\right] \mathrm{BF}_{4}\right]-, \quad\left[\mathrm{C}_{2} \mathrm{im}\right]\left[\mathrm{C}_{3} \mathrm{H}_{6} \mathrm{NH}_{2}\right] \mathrm{Br}-, \quad$ and $\left.\left[\mathrm{C}_{2} \mathrm{im}\right]\left[\mathrm{C}_{3} \mathrm{H}_{6} \mathrm{NH}_{2}\right] \mathrm{BF}_{4^{-}}\right)$(Table 1). The goal of this research is to develop a new series of functionalized imidazoliumbased ILs for the adsorption of pirimicarb from orchard wastewater. The morphology, crystallization, chemical structure, and textural characteristics of the various types of imidazolium-based ILs that were produced were studied. The effects of IL type, contact time, carbamate concentration, and temperature on removal efficiency were studied. Then, using adsorption kinetics, isotherms, and thermodynamic models, the adsorption performance was assessed. Possible carbamate adsorption mechanisms onto ILs and the regeneration and recycling studies of the adsorption process were discussed in detail. This research presents functionalized ILs as novel adsorbent materials, for adsorbing and removing carbamate from orchards in a complex environmental medium and projecting their use in large-scale wastewater treatment processes.

\section{Materials and Methods}

2.1. Materials. All chemicals and reagents used were of Sigma Aldrich Company and were of analytical grade.

2.2. Synthesis of Functionalized Imidazolium-Based Ionic Liquids. The chemical structure and its molecular models of the synthesized ILs are shown in Table 1. As shown in Figure 1, the synthesized functional imidazolium-based ILs were prepared by the following procedures.

2.2.1. Synthesis of $[\mathrm{im}]\left[\mathrm{C}_{3} \mathrm{H}_{6} \mathrm{NH}_{2}\right] \mathrm{Br}^{-}$. In a typical experiment, $5 \mathrm{mmol}$ imidazole was added to 2-bromopropyl amine in $20 \mathrm{~mL}$ toluene and heated to $50^{\circ} \mathrm{C}$ under continuous reflux for 24 hours to form an oily colorless macrodroplet, which was then iced for 3 hours before being washed repeatedly with ethyl acetate to remove the unreacted materials. S1 was assigned to the synthesized IL ([im] $\left.\left[\mathrm{C}_{3} \mathrm{H}_{6} \mathrm{NH}_{2}\right] \mathrm{Br}^{-}\right)$.

2.2.2. Synthesis of $\left.[\mathrm{im}]\left[\mathrm{C}_{3} \mathrm{H}_{6} \mathrm{NH}_{2}\right] \mathrm{BF}_{4}\right]^{-}$. IL based on the $\mathrm{BF}_{4}{ }^{-}$ anion was synthesized using sodium tetrafluoroborate and an ion exchange reaction mechanism. Using toluene $(20 \mathrm{~mL})$ as a solvent, a known amount of (S-1) was added to $5 \mathrm{mmol}$ sodium tetrafluoroborate. For anionic exchange of bromide ion with tetrafluoroborate ion, the mixture was refluxed under heating for 24 hours. After 2-3 hours of condensation and washing, the crude liquid (ethyl acetate) was transformed into pale yellow droplets. S-2 was assigned to the product $\left.\left([\mathrm{im}]\left[\mathrm{C}_{3} \mathrm{H}_{6} \mathrm{NH}_{2}\right] \mathrm{BF}_{4}\right]^{-}\right)$.

2.2.3. Synthesis of $\left(\left[\mathrm{C}_{2} \mathrm{im}\right]\left[\mathrm{C}_{3} \mathrm{H}_{6} \mathrm{NH}_{2}\right] \mathrm{Br}^{-}\right)$. An equimolar ( $5 \mathrm{mmol}$ ) ratio of 2-ethyl imidazole and 2-bromopropyl amine hydrobromide was dissolved in $20 \mathrm{~mL}$ toluene under constant stirring and reflux at $50^{\circ} \mathrm{C}$. A condensed oily layer 
TABLE 1: The chemical structures of the studied imidazolium-based ILs.

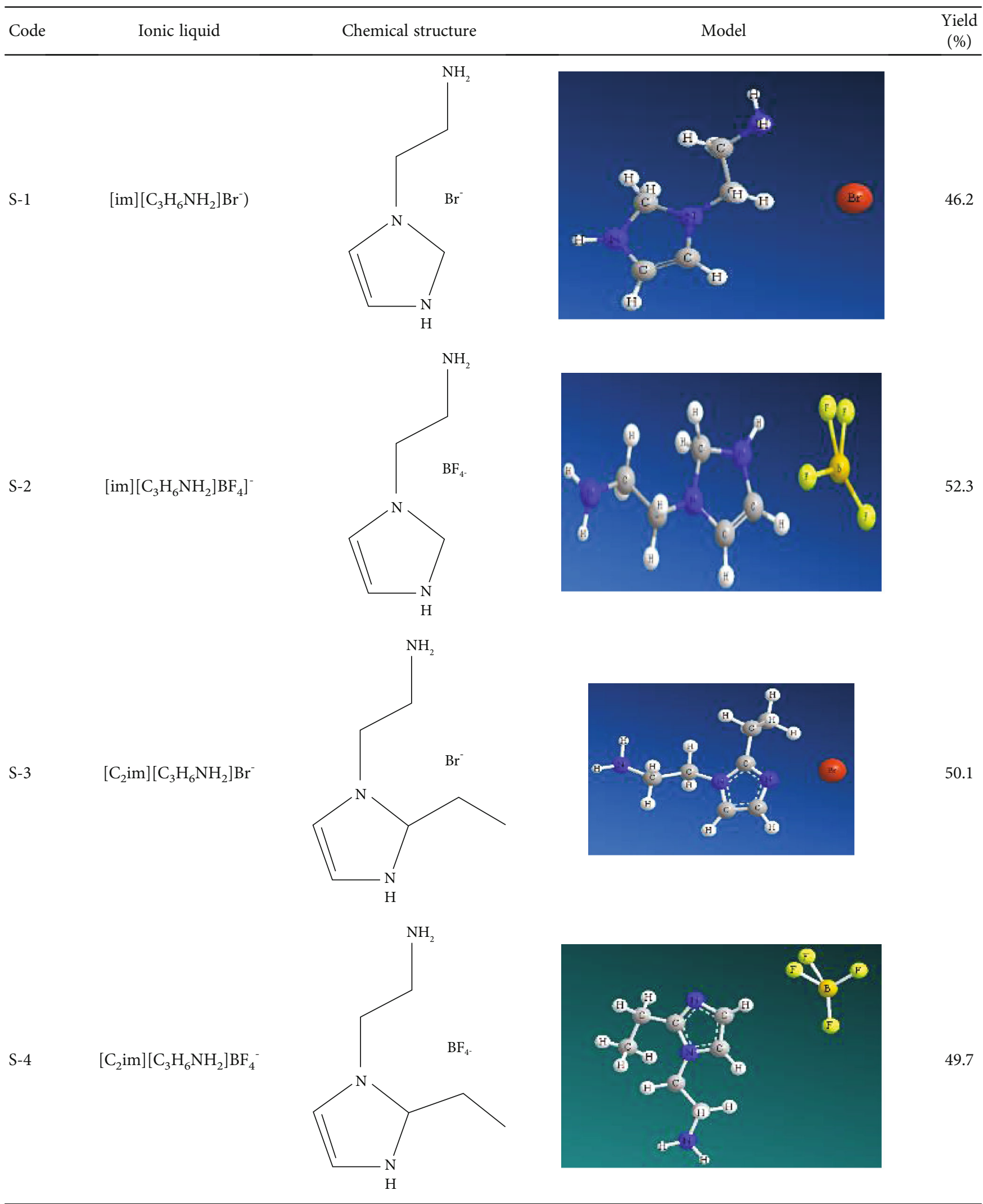




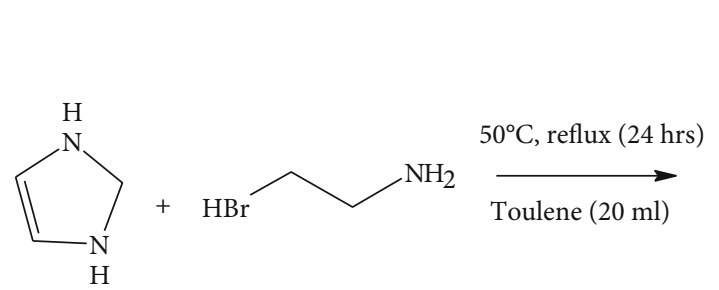<smiles>NCC[NH+]1C=CNC1</smiles><smiles>NCCN1C=CNC1</smiles><smiles>NCCN1C=CNC1</smiles>

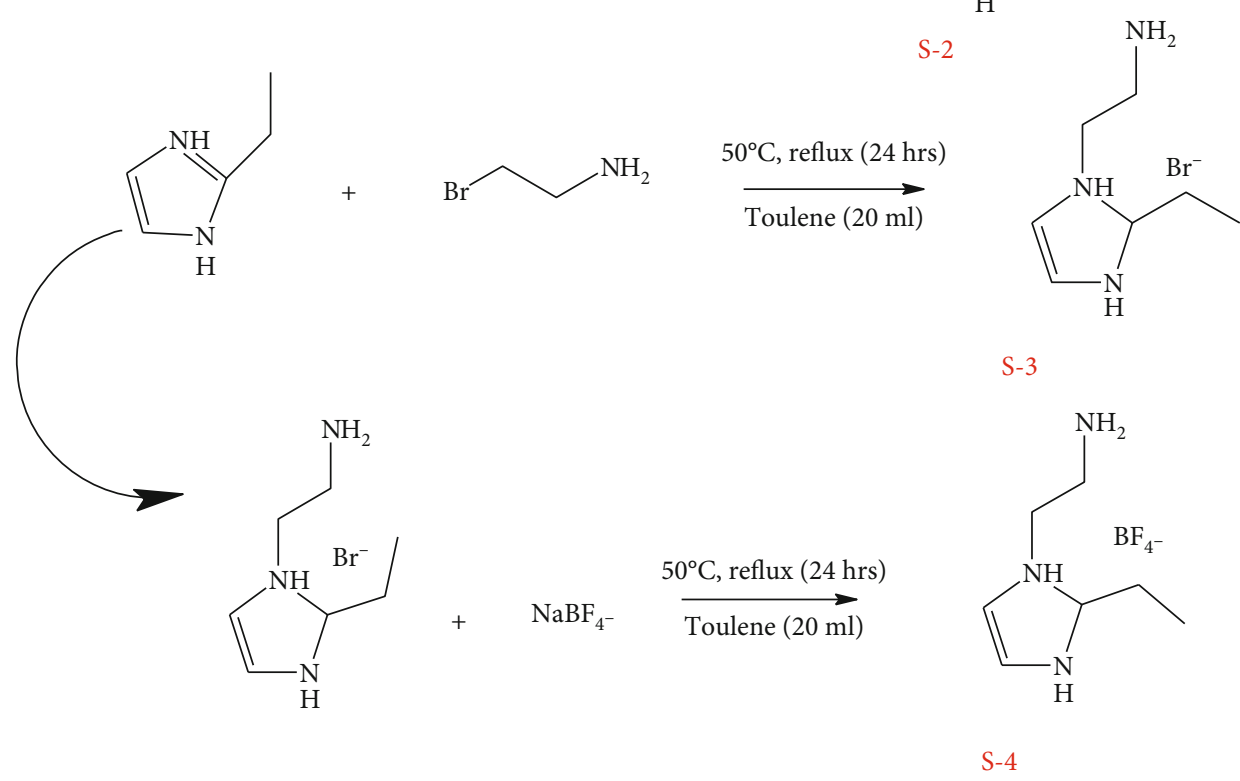

Figure 1: Schematic diagram of synthetic route of imidazolium-based ionic liquids.

washed with ethyl acetate was turned into new IL named as ([im] $\left.\left[\mathrm{C}_{3} \mathrm{H}_{6} \mathrm{NH}_{2}\right] \mathrm{Br}^{-}\right)$with code given as S-3.

2.2.4. Synthesis of $\left[\mathrm{C}_{2} \mathrm{im}^{-}\left[\mathrm{C}_{3} \mathrm{H}_{6} \mathrm{NH}_{2}\right] \mathrm{BF}_{4}^{-}\right.$. Following the above-mentioned protocol for S-3, $\left(\left[\mathrm{C}_{2} \mathrm{im}\right]\left[\mathrm{C}_{3} \mathrm{H}_{6} \mathrm{NH}_{2}\right] \mathrm{BF}_{4}{ }^{-}\right)$ was synthesized using an ion exchange reaction mechanism $\left(\mathrm{Br}^{-}\right.$to $\left.\mathrm{BF}_{4}^{-}\right)$. The sample was coded as S-4.

2.2.5. Characterization of Adsorbents and Adsorption Studies. The detailed characterization and adsorption experiments are stated in supporting information (Supp.1, and Supp.2), respectively.

\section{Results and Discussion}

The new imidazolium-based ILs were used to test the extraction of pirimicarb. Table S-1 lists the characteristics of pirimicarb. The pirimicarb was derived from real wastewater collected from orchard gardens in the District of Jhelum, Pakistan, which had recently been sprayed with the pesticide (see Supporting Information Fig.S-1). The designation of new ionic liquids with an aromatic and double-bond moiety could open up a new frontier in the separation studies of carbamate compounds due to the aromatic characteristics of pirimicarb. Figure 1 depicts the ILs studied and their synthesis. These ILs have high redox stability, are simple to synthesize, and have a low viscosity.

3.1. Characteristics of the Prepared Imidazolium-Based ILs. FTIR was used to identify changes in the functional groups of the various ILs that had been prepared. In pure ILs, the skeleton stretching vibration of the imidazolium ring can be assigned by two peaks at 1580 and $1470 \mathrm{~cm}^{-1}$, which provide clear evidence for the successfully prepared products (S1 to S-4) [21]. The total incorporation of ILs with alkyl groups and the formation of new functional groups 

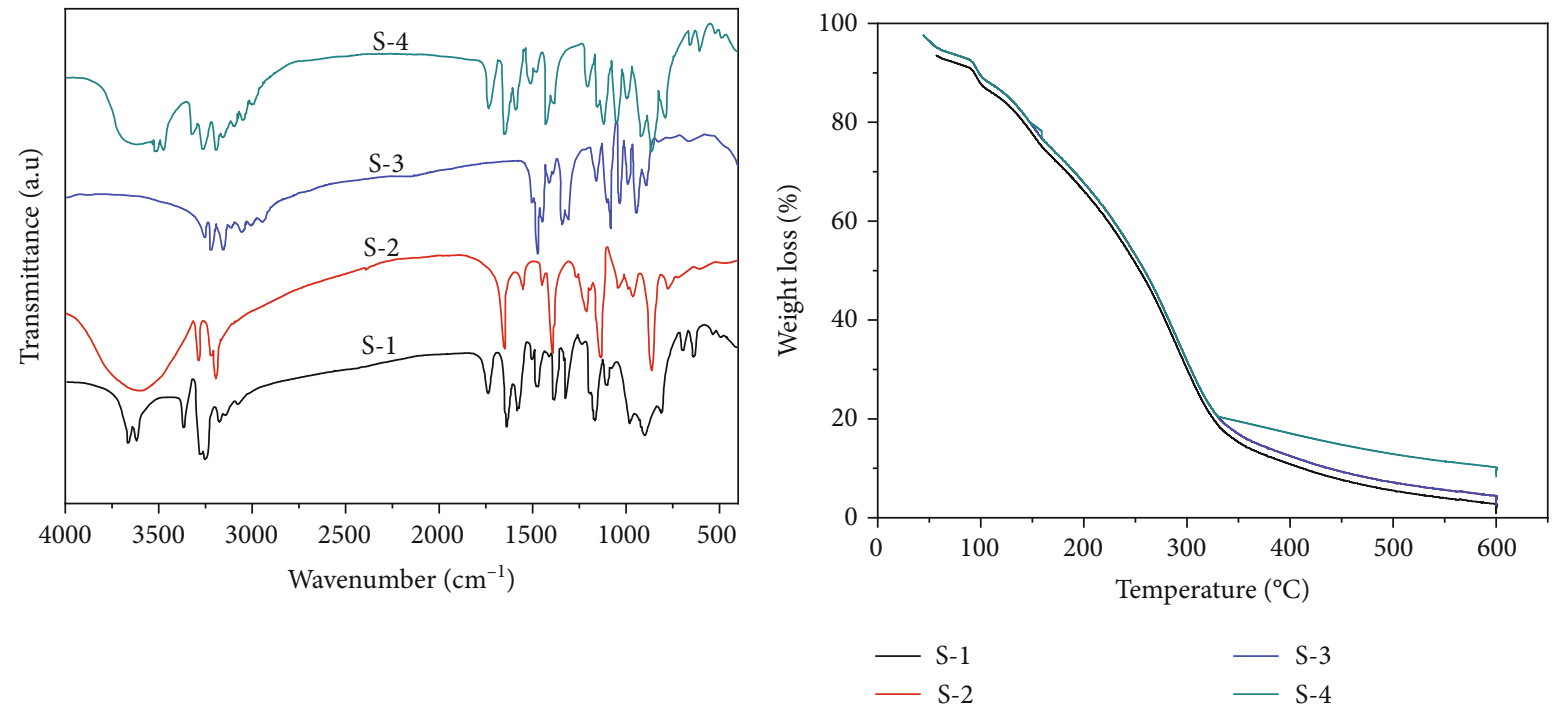

(a)

(b)

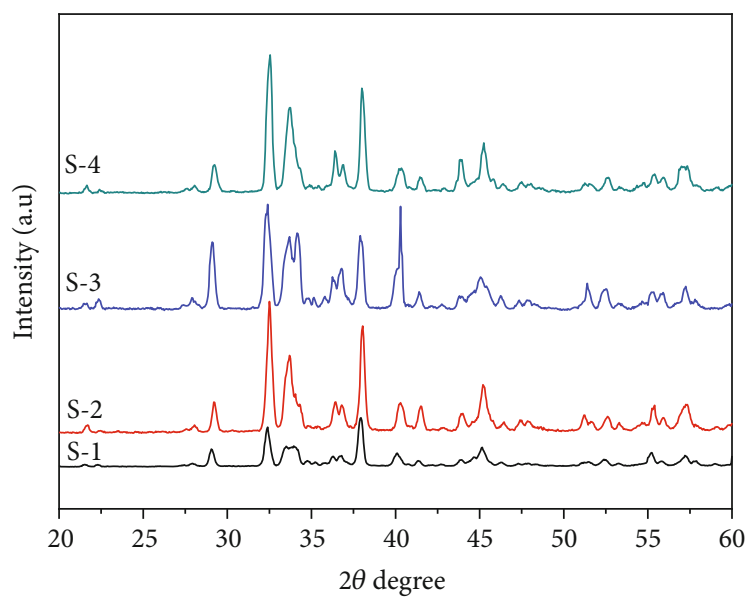

(c)

Figure 2: (a) FTIR, (b) TGA, and (c) XRD of the prepared imidazolium-based ILs.

composites with completely different properties can be stated as the disappearance or less intense of former pure ILs stretching vibration bands.

The change in intensity of sample S-1 between 2800 and $3000 \mathrm{~cm}^{-1}$ indicated the presence of several alkyl groups [22]. The conjugated strong peaks at 1580 and $1633 \mathrm{~cm}^{-1}$ were caused by the imidazolium ring's symmetric $\mathrm{C}=\mathrm{N}$ and symmetric $-\mathrm{C}=\mathrm{C}$ - bonds, respectively, indicating the presence of imidazolium cations [15]. The peaks at $3650 \mathrm{~cm}^{-1}$ represent $\mathrm{N}-\mathrm{H}$ stretching, whereas the stretching vibration of the $-\mathrm{OH}$ bond is due to the hydrobromide anion, which appears at $3300 \mathrm{~cm}^{-1}$ and helps form hydrogen bonds with pirimicarb [23]. The symmetric aromatic $\mathrm{C}-\mathrm{H}$ group in imidazolium cations of ILs was revealed by the peak at $3150 \mathrm{~cm}^{-1}$ [24]. Furthermore, the imidazole cation's C-H stretching and bending were measured at $3100-3150 \mathrm{~cm}^{-1}$ and $1450 \mathrm{~cm}^{-1}$, respectively [25]. Furthermore, the FTIR spectra in Figure 2(a) revealed that the peaks at $1640 \mathrm{~cm}^{-1}$ are due to $-\mathrm{C}=\mathrm{C}$ stretching vibration $[26]$. $\mathrm{C}=\mathrm{N}$ and $\mathrm{C}-\mathrm{N}$ between the nitrogen of the imidazolium ring and the first carbon, respectively, are responsible for the peaks at 1417 and $1145 \mathrm{~cm}^{-1} 1$, which are attributed to the functional group between the imidazolium ring and alkyl groups [27]. In comparison to bromide-containing IL counterparts, the FTIR spectra of samples S-2 and S-4, which are substituted by $\mathrm{BF}_{4}^{-}$, show similar peaks but less shifted vibrational bands. The stretching vibration of anion $\mathrm{BF}_{4}{ }^{-}$causes a new peak in the spectra of samples S-2 and S-4 at $1130 \mathrm{~cm}^{-1}$ and $1050 \mathrm{~cm}^{-1}$, respectively $[28,29]$. The B-F peak (1050$1070 \mathrm{~cm}^{-1}$ ) due to the long cationic group accompanying $\mathrm{BF}_{4}^{-}$is supported by the literature [28]. At $850 \mathrm{~cm}^{-1}, \mathrm{C}-\mathrm{N}$ (bop) can also be seen.

Thermogravimetric analysis (TGA) was used to collect data on the thermal degradation of the total \% mass loss of imidazolium-based ILs that had been prepared. The results are plotted in Figure 2(b), indicating that the thermal stability of the four synthesized ionic liquids is ranked S-4, S-3, S2 , and $\mathrm{S}-1$. At $100^{\circ} \mathrm{C}$, the desorption of adsorbed water onto the surface of the samples resulted in a small weight loss. Small initial weight loss is due to remaining organic solvents 


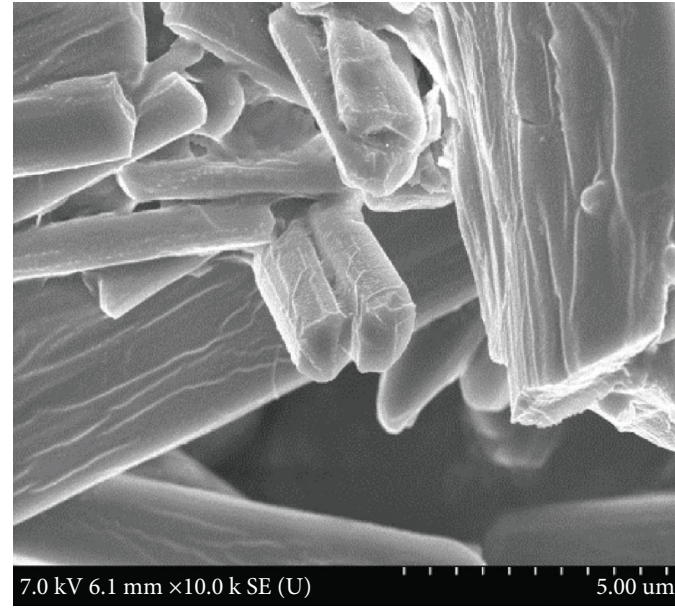

(a)

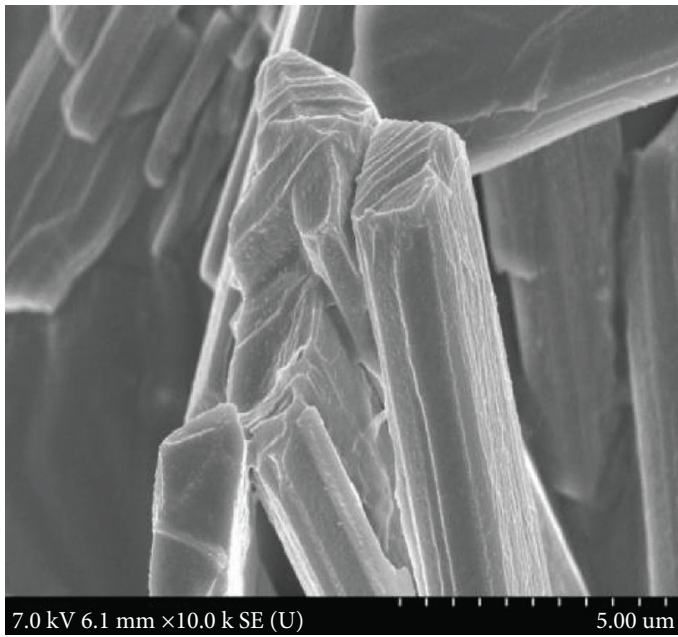

(c)

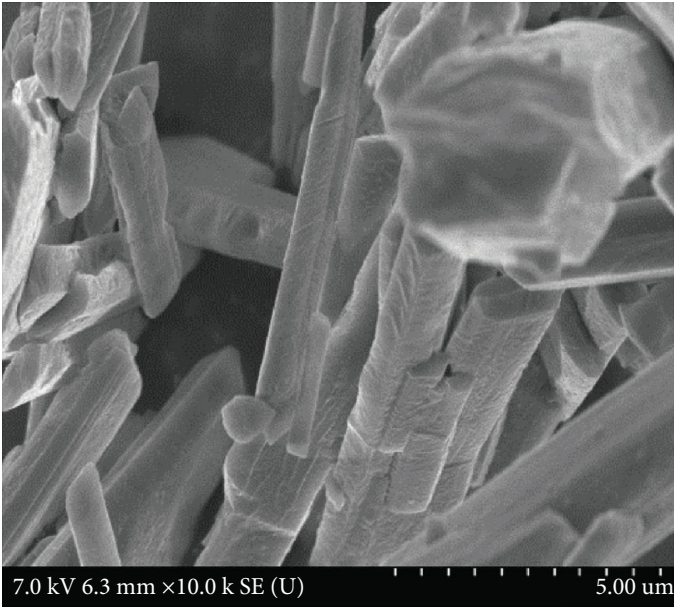

(b)

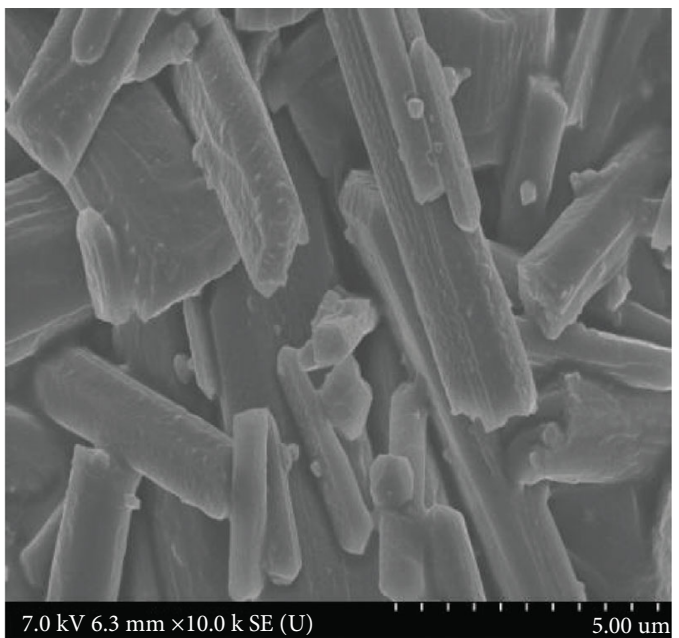

(d)

Figure 3: SEM of imidazolium-based ionic liquids: (a) S-1, (b) S-2, (c) S-3, and (d) S-4.

TABLE 2: BET isotherm of synthesized imidazolium-based ILs.

\begin{tabular}{lcccc}
\hline Properties & S-1 & S-2 & S-3 & S-4 \\
\hline BET surface area $\left(\mathrm{m}^{2} / \mathrm{g}\right)$ & 289 & 296 & 300 & 292 \\
Micropore volume $\left(\mathrm{cm}^{3} / \mathrm{g}\right)$ & 0.04 & 0.07 & 0.09 & 0.03 \\
Micropore area $\left(\mathrm{m}^{2} / \mathrm{g}\right)$ & 57 & 59 & 61 & 52 \\
\hline
\end{tabular}

and physically adsorbed water due to the hydrophilic nature of imidazolium-based ILs at temperatures between 100 and $200^{\circ} \mathrm{C}$ [30]. Then there was the 80 percent weight loss for all samples at temperatures ranging from room temperature to $323^{\circ} \mathrm{C}$, which was attributed to the breakdown of the organic moieties. It can be seen from the curves that the samples are thermally stable above $300^{\circ} \mathrm{C}$, which is useful information for the thermal stability of different ILs. Above $323^{\circ} \mathrm{C}$, it can thus be concluded that the sample S-4 has the highest thermal stability which indicates that the stability increases with the increase in alkyl chain length of cations while the samples containing $\mathrm{BF}_{4}^{-}$are effectively thermally stable than samples containing $-\mathrm{Br}^{-}$.
X-ray diffraction analysis was used to determine the crystallinity and purity of the synthesized ILs (Figure 2(c)). The sharp peaks and high intensity of reflections revealed that all samples had well-crystalline structures (S-1 to S-4). The reflections observed in the diffraction patterns of samples S-2 and S-4 were narrower and more intense than those observed in the diffraction patterns of samples S-1 and S-3, indicating that the $\mathrm{BF}_{4}{ }^{-}$treatment crystallized better than the $\mathrm{Br}^{-}$treatment. Furthermore, the broadening of diffraction peaks in samples indicated very small crystallite sizes in the 22-24 $\mathrm{nm}$ range. The samples were all pure phases in every case. There are small shifts and differences in the intensity of the XRD diffraction patterns, indicating that the crystal structure of imidazolium-based ILs has changed as a result of the reaction.

According to the Scherrer equation, it can be noted that the crystal size of synthesized ILs decreased from $24.10 \mathrm{~nm}$ for sample S-1 to $22.65 \mathrm{~nm}$ for sample S-2, but it remained almost the same $(22.30 \mathrm{~nm})$ for sample $S-3$ and $22.70 \mathrm{~nm}$ for sample S-4.

Figure 3 shows the SEM images and surface morphology of the functionalized imidazolium-based ILs. All of the data 


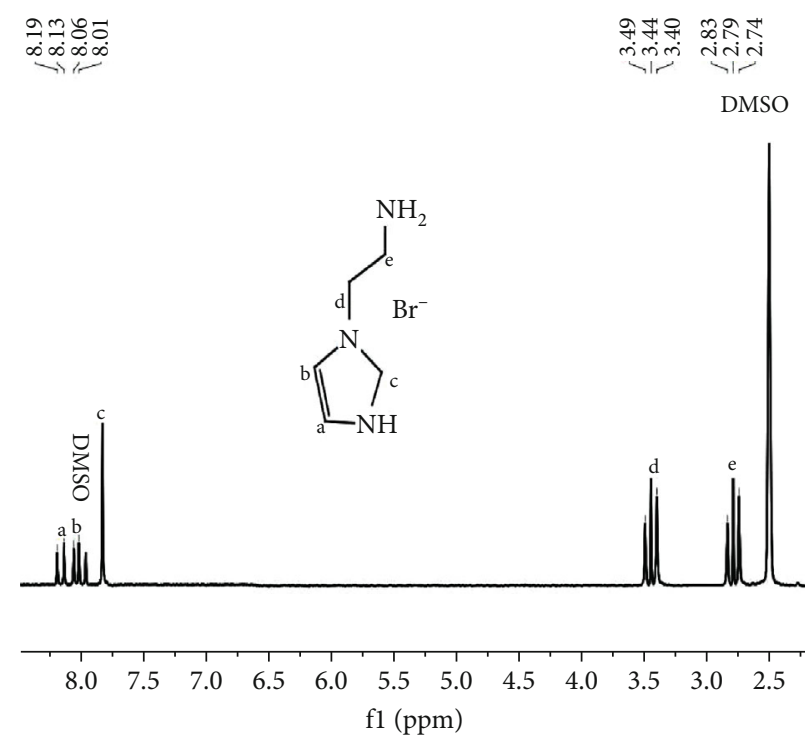

(a)

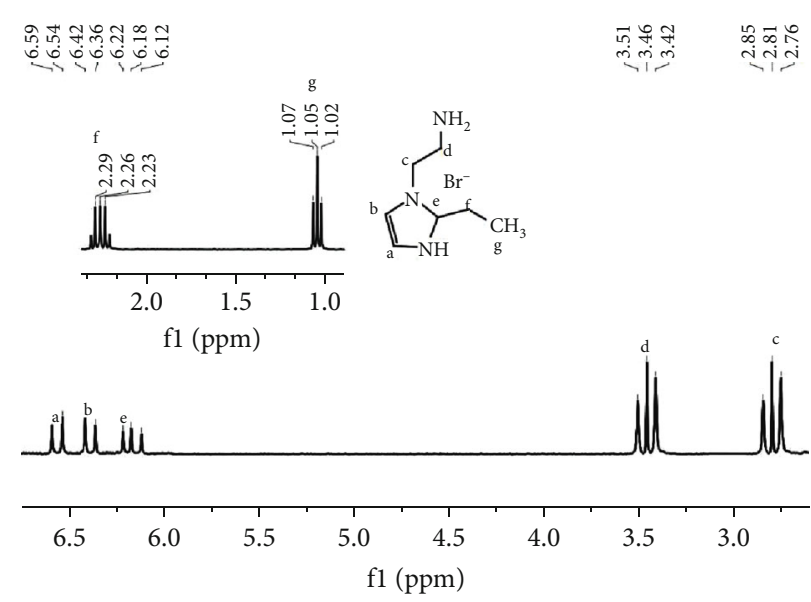

(b)

Figure 4: ${ }^{1} \mathrm{H}$ NMR of (a) S-1 and (b) S-3 based on imidazolium-based ILs.

was collected at a magnification of $10 \mathrm{~K}$, and a micrograph with a size of $5 \mathrm{~m}$ was chosen. The well-ordered arrays of agglomerated flat rod-like sheets, which were typical morphology of periodic imidazolium-based ILs, are clearly visible. When comparing sample S-3 to other samples, the highest uniformity was found, indicating the presence of various imidazolium-based ILs. When the carbon chain was increased from $\mathrm{C} 1$ to C2 (S-3, S-4), imidazolium-based ILs became more assembled, predicting cleared rod-like structures, as shown in Figure 3. These characteristics gain support from the cited literature [31] as well.

The specific surface area, micropore volume, and micropore area of as prepared imidazolium-based ILs are listed in Table 2, to obtain additional information regarding the textural properties of the prepared ILs. The surface area of the reported imidazolium-based ILs was much smaller in all cases than the ones found in this study [14]. The use of the solvent in the preparation resulted in a large surface area and porosity, also supported by cited research [32]. For all samples, there are no obvious changes in surface area or pore volume.

Ionic liquids based on cationic composition (imidazole, 2-ethyl imidazole) were subjected to ${ }^{1} \mathrm{H}$ NMR analysis for structure elucidation. ${ }^{1} \mathrm{H}$ NMR spectra of samples $\mathrm{S}-1$ and S-3 were taken at $400 \mathrm{MHz}$ using dimethyl sulfoxide (DMSO) as solvent as shown in Figure 4.

The strength of the $\mathrm{C}(2)-\mathrm{H}$ bond can be seen in the ${ }^{1} \mathrm{H}$ NMR chemical shift values $(\delta, \mathrm{ppm})$ of imidazoliumbased ILs such as sample S-1, which are $2.79(2 \mathrm{H}, \mathrm{t}$, $\left.\mathrm{CH}_{2}\right), 3.44\left(2 \mathrm{H}, \mathrm{t}, \mathrm{CH}_{2}\right), 7.9\left(2 \mathrm{H}, \mathrm{d}, \mathrm{CH}_{2}\right), 8.13(1 \mathrm{H}, \mathrm{d}$, $\mathrm{CH})$, and $8.19(1 \mathrm{H}, \mathrm{d}, \mathrm{CH})$, indicating different stereochemistry of protons [33]. The doublet (d) peak at $7.9 \mathrm{ppm}$ shows the influence of $\mathrm{NH}$ groups on protons from both sides, as can be seen from the results. Protons present on neighboring positions at carbon " $\mathrm{d}$ " and "e," respectively, can be attributed to two triplet ( $\mathrm{t}$ ) peaks at 2.79 and $3.44 \mathrm{ppm}$. The splitting of peaks into a triplet is caused by neighboring protons of the imidazole ring.
Two doublet peaks at carbon position "a" and "b" (8.13 and $8.19 \mathrm{ppm}$ ) are designated to protons present inside the imidazole ring. It can be due to the change in the proton environment due to chemical shifts at carbon "a" and carbon "b" [34].

Similarly, in sample S-3, the chemical shifts are noted at $\delta / \mathrm{ppm}: 1.05\left(3 \mathrm{H}, \mathrm{t}, \mathrm{CH}_{3}\right), 2.23-2.29(2 \mathrm{H}, 2.26, \mathrm{qd}$, $\left.\mathrm{CH}_{2}\right), 2.76-2.85\left(2 \mathrm{H}, \mathrm{t}, \mathrm{CH}_{2}\right), 3.42-3.51\left(2 \mathrm{H}, \mathrm{t}, \mathrm{CH}_{2}\right)$, $6.18(1 \mathrm{H}, \mathrm{t}, \mathrm{CH}), 6.36-6.42(1 \mathrm{H}, \mathrm{d}, \mathrm{CH})$, and 6.54-6.59 $(1 \mathrm{H}, \mathrm{d}, \mathrm{CH})$. The quadrant at $\delta 2.2 .3-2.29 \mathrm{ppm}$ is due to the influence of $\mathrm{CH}_{3}$ and $\mathrm{CH}$ present in the surroundings of carbon position " $\mathrm{f}$."

3.2. Adsorption of Pirimicarb by the Functionalized Imidazolium-Based ILs. The efficiency of the prepared materials as a potential adsorbent was investigated after the successful synthesis of various types of imidazolium-based ILs. The synergy between two effects, (i) the counter anions (i.e., $\mathrm{Cl}^{-}$and $\mathrm{BF}_{4}^{-}$) and (ii) the various cation substituents as a hydrocarbon chain attached with imidazolium-based ILs, initially affected the adsorption of pirimicarb onto the various types of imidazolium samples. This discovery revealed that the effect of $\mathrm{BF}_{4}{ }^{-}$on adsorption characteristics is more noticeable than the effect of $\mathrm{Br}^{-}$and that the longer chain length has a significant impact on the adsorption process. It is possible that the lower effect of $\mathrm{Br}^{-}$-based imidazolium adsorbent is due to $\mathrm{Br}^{-}$'s complete dissociation in water, whereas hydrophobic $\mathrm{BF}_{4}{ }^{-}$anions are very stable in solution and nearly immiscible [35]. However, as the chain of hydrocarbons lengthens, the effect of BF4- diminishes (sample S4). The adsorption follows the sequence S-3 (75\%) > S-2 $(74 \%)>$ S-4 $(58 \%)>$ S-1 (18\%).

According to the literature, the weaker the intramolecular hydrogen bonding between the $\mathrm{C}(2)-\mathrm{H}$ and the anions, the longer the $\mathrm{N}$-alkyl side chains [36]. As a result, longer alkyl chain ILs have a greater ability to separate pirimicarb. This behavior can be seen in S-1, which has a shorter side 
chain than S-3, resulting in less interaction to form hydrogen bonds with pirimicarb and due to the close proximity of the cation and $\mathrm{Br}^{-}[3,14]$. Due to the large volume used by the benzyl group (in pirimicarb) matched to the allyl substituent, S-1's ability to extract pirimicarb from liquid outperformed S-3's, and as a result of the steric hindrance caused by the larger benzyl group, the chloride ion was unable to form an $\mathrm{H}$-bond with phenol [37].

Following that, it is worth noting that the distance between the chloride ion and the cation is optimal for forming a hydrogen bond with phenol $[3,14]$. The branched structure has higher hydrophilicity than the linear structure [38].

The change in separation capability has two justifications. For starters, it has to do with the ILs' ability to form hydrogen bonds with pirimicarb. The main mechanism in samples S-1 and S-3 is the bromide ion (Br-) of the ILs, which acts as an electron donor to the pirimicarb groups containing $\mathrm{N}$ and/or $\mathrm{O}$. The $\mathrm{Br}^{-}$ion has a higher chance of making contact with pirimicarb, resulting in a higher degree of hydrogen bonding in the system. Secondly, their ${ }^{1} \mathrm{H}$ NMR spectrum demonstrates the role of aromatic moieties and unsaturated substitutes in the stronger interaction of ILs with the aromatic ring of pirimicarb. This is due to unsaturated substitutions on the cationic imidazolium ring, which can attract aromatic compounds more efficiently than their alkyl counterparts [18]. The intensity of the $\mathrm{C}(2)-\mathrm{H}$ can be endorsed from the ${ }^{1} \mathrm{H}$ NMR chemical shift $(\delta, \mathrm{ppm})$ of the ILs. The higher the $\mathrm{C}(2)-\mathrm{H}$ chemical shift, the stronger its interaction with the anion, thus decreasing the possibility of the anion to form H-bonding with pirimicarb [34]. Another point to consider is how the larger ethyl propyl group hampered the ability of the $\mathrm{BF}_{4}{ }^{-}$ions to form a $\mathrm{H}$ bond with pirimicarb in samples S-2 and S-4 (S4 is lower as a result of the hindrance). As a result, it is important to remember that there is an ideal distance between chloride ions and cations for forming a hydrogen bond with pirimicarb $[3,14,38]$. When the hydrophobicity of pirimicarb is lower, it offers dispersion, or/and hydrogen bond interactions appear to play a significant role in the separation capability of the studied ILs, this change is more pronounced.

The effect of contact time was investigated thoroughly from 5 to 200 minutes in the case of a dosage of $10 \mathrm{mg}$ in order to establish the equilibrium required for mass transfer between two immiscible phases. It can be observed that from 5 to $30 \mathrm{~min}$, the rejection capability was greatly improved (Figure 5). This pattern may have emerged as a result of the initial accumulation of pirimicarb on the active sites of ILs surface, with the majority of binding sites being used within 30 minutes. Further separation experiments are carried out above $30 \mathrm{~min}$ to confirm that the required equilibrium was reached, but there is no significant boost due to the lack of vacant adsorption sites [39]. The extraction capability of pirimicarb reached equilibrium after $30 \mathrm{~min}$, and thus, the duration of $30 \mathrm{~min}$ was active as the optimum time for extraction of pirimicarb from the orchard waste water. Literature studies show that $30 \mathrm{~min}$ is a good time to attain equilibrium in order to remove pesticides using functionalized ILs [40].

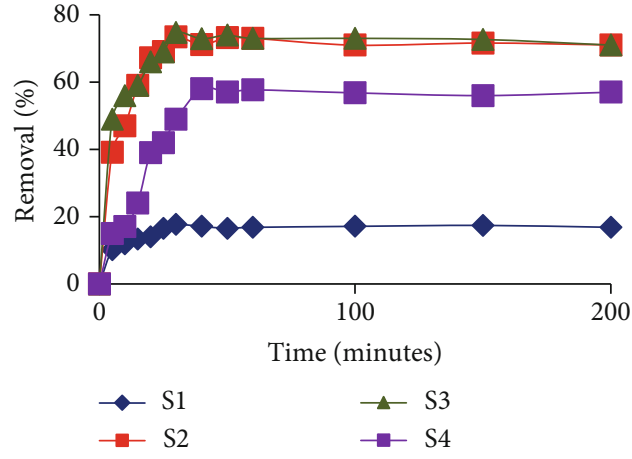

FIGURE 5: Removal of pirimicarb by synthesized ILs as a function of time.

The graphics plotted in Figure 6 can be used to analyze the effect of the initial pirimicarb concentration. According to logic, the separation efficiency decreases as the initial pirimicarb concentration rises, which could be due to pirimicarb equilibrium and saturation in ILs, as previously reported in the literature [6]. Experiments were carried out with varying lower concentrations of pirimicarb $(3,5$, and $7 \mathrm{mg} / \mathrm{L})$ in real wastewater from river streams, each sampled from a different area. Figure 6 shows that as the concentration of adsorbate increases from 3 to $5 \mathrm{mg} / \mathrm{L}$, separation efficiency increases, followed by a decrease in adsorption rate at $7 \mathrm{mg} / \mathrm{L}$. When interacting with pirimicarb at lower concentrations, the ratio of available binding sites on the surface of the adsorbent is larger [2]. It could be due to the saturation of active sites on the adsorbent surface. The $\mathrm{S}-3$ is effective at removing pirimicarb at concentrations of $5 \mathrm{mg} / \mathrm{L}$ or less after 30 minutes.

\subsection{Adsorption Isotherms, Kinetics, and Thermodynamic} Studies. The adsorption rate is a critical factor in practical water treatment. The mass transfer and adsorption mechanisms were studied using kinetic models of pseudo-firstorder, pseudo-second-order, and intraparticle diffusion (expressed in Table S-2). The deliberate correlations for the pseudo-first-kinetic and second-kinetic models, as listed in Table S-3, are close to unity, according to the obtained results. As a result, the pseudo-first-kinetic model is able to accurately predict pirimicarb adsorption kinetics on the surface of imidazolium-based ILs. Further, the chemisorption is not the rate-limiting for the process of adsorption which is maybe due to the degree and shape of porous available for adsorption, also supported by literature [41].

The intraparticle diffusion model [42] was applied to describe the competitive adsorption. The initial rate of intraparticle diffusion is obtained by linearization of the curve $q_{t}=a+k_{\text {int }}\left(t^{0.5}\right)$. The plot of $q_{t}$ against $t^{0.5}$ may present multilinearity [43]. As presented in Table S-2, the linear plots are owing to the macropore distributions that are the available sites for adsorption. The results indicate that three steps occur in the adsorption processes for imidazoliumbased ILs. The first linear step $\left(R^{2}-1\right)$ is dedicated to the external surface adsorption or instantaneous adsorption stage. The second portion is attributed to the gradual adsorption stage where the intraparticle diffusion is rate- 

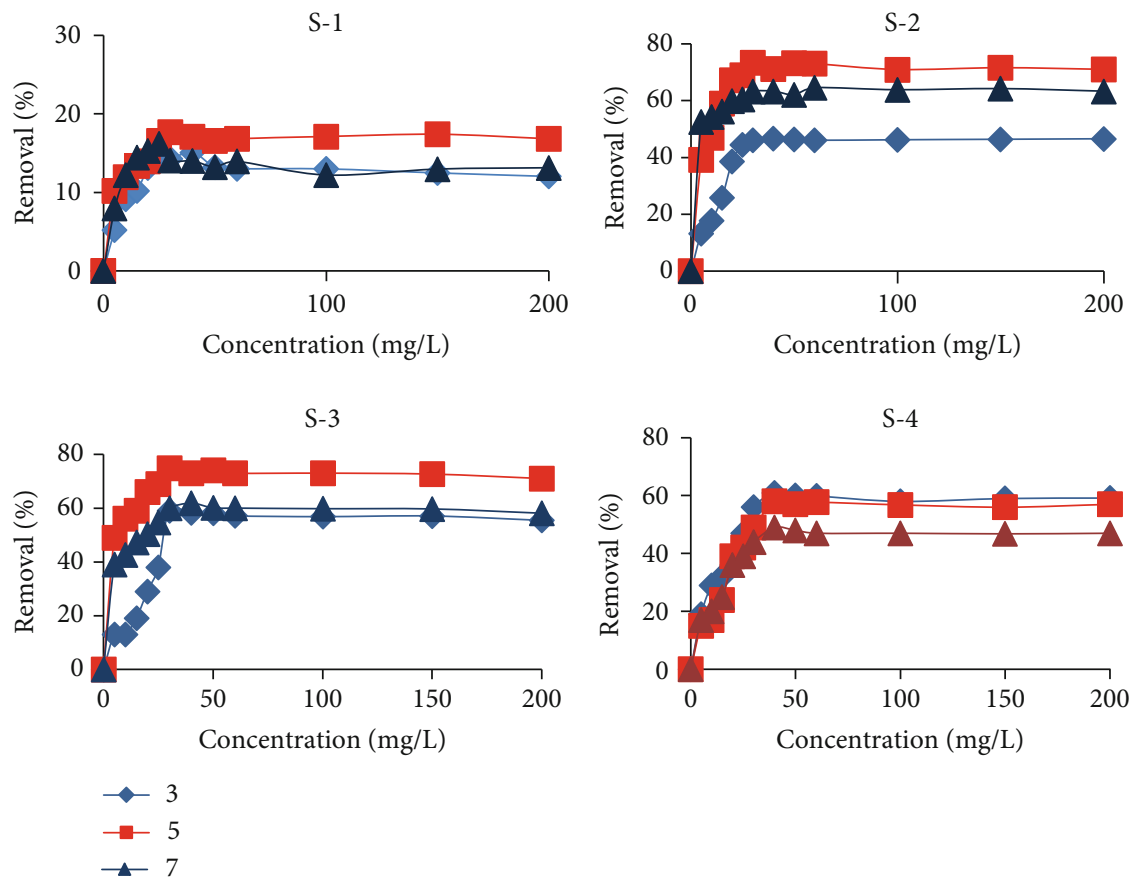

FIGURE 6: Removal of pirimicarb by the synthesized ILs as a function of concentration.

TABle 3: Kinetic parameters of pirimicarb adsorption onto prepared imidazolium-based ILs.

\begin{tabular}{ccccccccccc}
\hline & \multicolumn{3}{c}{} & \multicolumn{3}{c}{ Pseudo-first-order } & \multicolumn{3}{c}{ Pseudo-second-order } & \multicolumn{3}{c}{ Intraparticle diffusion } \\
& $K_{1}$ & $C_{\mathrm{o}}$ & $R^{2}$ & $q_{\mathrm{e}}$ & $K_{2}$ & $R^{2}$ & $K_{\text {Int }}$ & $R^{2}-1$ & $R^{2}-2$ & $R^{2}-3$ \\
\hline S-1 & 0.04 & 2.66 & 0.99 & 0.37 & 3.05 & 0.99 & 0.08 & 0.98 & 0.84 \\
S-2 & 0.04 & 1.00 & 0.92 & 0.40 & 0.38 & 0.65 & 0.26 & 0.92 & 1 & 0.89 \\
S-3 & 0.04 & 1.06 & 0.81 & 0.28 & 0.64 & 0.7 & 0.13 & 0.91 & 0.93 \\
S-4 & 0.06 & 1.20 & 0.99 & 0.59 & 0.21 & 0.8 & 0.25 & 0.99 & 0.89 \\
\hline
\end{tabular}

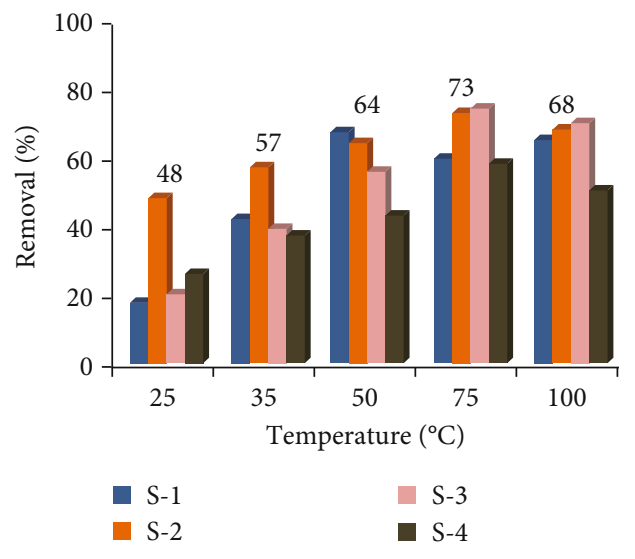

Figure 7: Removal of pirimicarb by synthesized ILs as a function of temperature.

controlled $\left(R^{2}-2\right)$ while the third portion is the final equilibrium stage $\left(R^{2}-3\right)$.

It could be discovered by comparing the $R^{2}$ values (Table 3), suggesting the sorption processes followed by the intraparticle diffusion model. It shows that the adsorp- tion process takes place through the following steps: (i) transport of pirimicarb in the bulk solution; (ii) film diffusion of these solute at the boundary layer or diffusion of pirimicarb from bulk solution to the external surface of ILs; (iii) the transfer of pirimicarb into the active sites and/or pores (intraparticle diffusion) at the ILs; and (v) diffusion through small pores of ILs.

Finally, based on the kinetic modeling results, it was demonstrated that the adsorption of the polluted pirimicarb onto the prepared imidazolium is governed by physisorption and intraparticle diffusion mechanisms.

The adsorption isotherm is a useful tool for determining adsorption efficiency, which is based on information about the reaction's feasibility as well as the surface properties of the synthesized ILs. At different initial concentrations, Langmuir, Freundlich, and Temkin were used. Table S-2 shows the linear plotting of these adsorption isotherms. Table S-3 shows that using the Langmuir model to simulate adsorption onto imidazolium-based ILs yields a better fit for the experimental adsorption equilibrium, which is indicative of pirimicarb adsorption onto imidazolium-based ILs as monolayer coverage and constant adsorption energy. 
TABLE 4: Thermodynamic studies of pirimicarb removal using synthesized ILs.

\begin{tabular}{|c|c|c|c|c|c|c|}
\hline Sample & Temp. (K) & $K_{\mathrm{d}}$ & $\Delta G\left(\mathrm{~kJ} \mathrm{~mol}^{-1}\right)$ & $E_{\mathrm{a}}\left(\mathrm{kJ} \mathrm{mol}^{-1}\right)$ & $\Delta H=$ slope $\times R / 1000$ & $\Delta S=($ intercept $\times R) / 1000$ \\
\hline \multirow{5}{*}{ S-1 } & 298 & 41.07 & -9.21 & 8.11 & \multirow{5}{*}{26.39} & \multirow{5}{*}{0.06} \\
\hline & 308 & 26.11 & -8.35 & 9.54 & & \\
\hline & 323 & 16.75 & -7.57 & 11.20 & & \\
\hline & 348 & 9.631 & -6.46 & 13.47 & & \\
\hline & 373 & 4.635 & -4.76 & 16.92 & & \\
\hline \multirow{5}{*}{ S-2 } & 298 & 84.88 & -11.00 & -4.91 & \multirow{5}{*}{17.43} & \multirow{5}{*}{0.02} \\
\hline & 308 & 83.27 & -11.32 & -5.03 & & \\
\hline & 323 & 65.99 & -11.25 & -4.65 & & \\
\hline & 348 & 37.40 & -10.33 & -3.32 & & \\
\hline & 373 & 22.62 & -9.67 & -2.05 & & \\
\hline \multirow{5}{*}{ S-3 } & 298 & 78.52 & -10.81 & -1.60 & \multirow{5}{*}{20.58} & \multirow{5}{*}{0.03} \\
\hline & 308 & 76.76 & -11.12 & -1.59 & & \\
\hline & 323 & 75.05 & -11.60 & -1.61 & & \\
\hline & 348 & 30.84 & -9.78 & 0.83 & & \\
\hline & 373 & 16.70 & -8.73 & 2.80 & & \\
\hline \multirow{5}{*}{ S-4 } & 298 & 78.00 & -10.79 & 4.08 & \multirow{5}{*}{25.50} & \multirow{5}{*}{0.05} \\
\hline & 308 & 49.04 & -9.97 & 5.40 & & \\
\hline & 323 & 32.91 & -9.38 & 6.74 & & \\
\hline & 348 & 18.20 & -8.27 & 8.84 & & \\
\hline & 373 & 9.54 & -7.00 & 11.62 & & \\
\hline
\end{tabular}

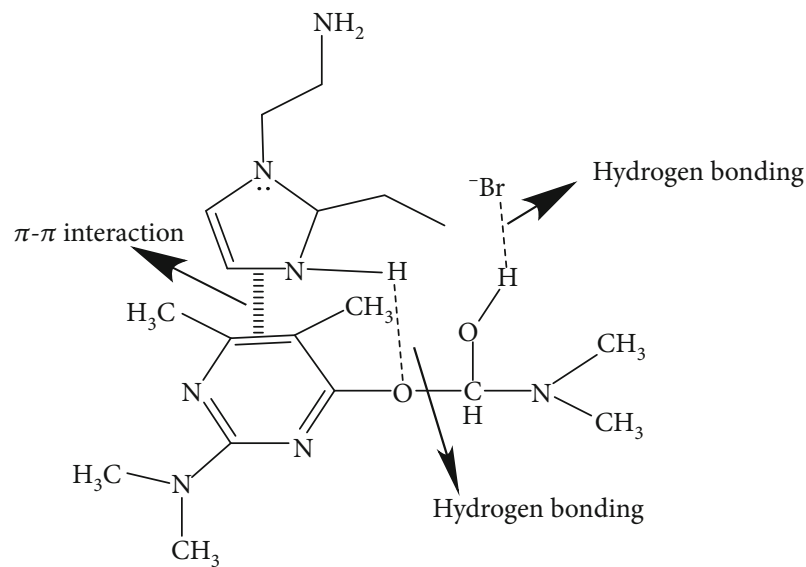

(a)

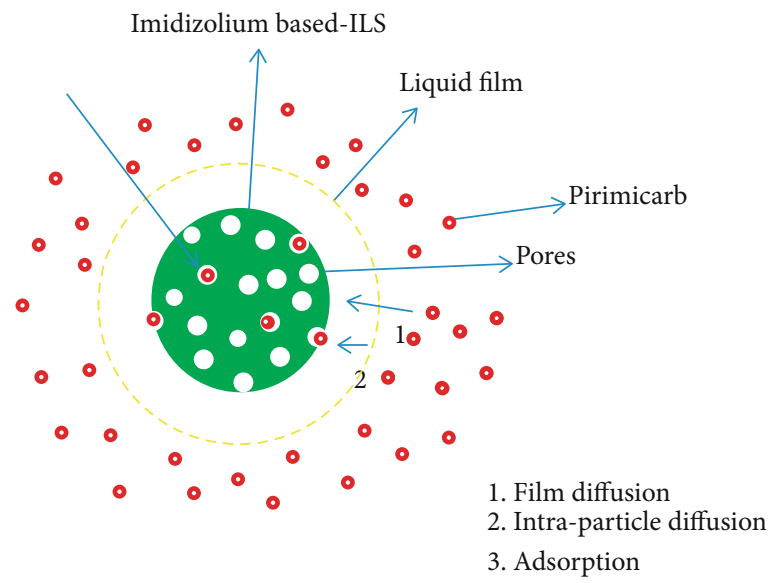

(b)

Figure 8: (a) Mechanism of removal of pirimicarb with $\left(\left[\mathrm{C}_{2} \mathrm{im}\right]\left[\mathrm{C}_{3} \mathrm{H}_{6} \mathrm{NH}_{2}\right] \mathrm{Br}\right.$ ) by $\pi-\pi$ interaction and $\mathrm{H}$-bonding, and (b) schematic diagram of physical mechanism with steps for adsorption of pirimicarb onto imidazolium-based ILs.

Furthermore, pirimicarb and the prepared imidazolium-based IL-bending sites have a strong electrostatic attraction [44]. The Temkin adsorption isotherm was developed to determine the heat of adsorption liberation. The adsorption system based on the heat and pirimicarb sorption processes was analyzed using a uniform distribution of binding energies up to a maximum binding energy, as shown in Table S-3.

The effect of temperature on the removal efficiency of pirimicarb was studied thoroughly at the temperature range $25-100^{\circ} \mathrm{C}$ at the constant dose of $10 \mathrm{mg} / \mathrm{L}$, initial concentration, and contact time of $60 \mathrm{~min}$, and the experimental data are plotted in Figure 7 . The temperature was varied from $25^{\circ} \mathrm{C}$ onward by the varying intervals of $10,15,20$, and 30 , respectively. It is clear that increasing the reaction, temperature increases the pirimicarb removal efficiency. It can be justified from a thermodynamic standpoint because the adsorption process is endothermic in nature and controlled by the enthalpy term [45]. At $75^{\circ} \mathrm{C}$, which is assumed to be the solution's equilibrium temperature, the maximum adsorption of 73 percent of pirimicarb was obtained. This could be because as the temperature rises, the randomness of pirimicarb decreases, resulting in increased adsorption. With each increase in temperature after that temperature, the adsorption decreases. 
TABLE 5: Recyclability of functionalized ILs up to six adsorption cycles.

\begin{tabular}{lcccccc}
\hline Adsorbents & $\begin{array}{c}\text { 1st } \\
\text { cycle }\end{array}$ & $\begin{array}{c}\text { 2nd } \\
\text { cycle }\end{array}$ & $\begin{array}{c}\text { 3rd } \\
\text { cycle }\end{array}$ & $\begin{array}{c}4 \text { th } \\
\text { cycle }\end{array}$ & $\begin{array}{c}\text { 5th } \\
\text { cycle }\end{array}$ & $\begin{array}{c}\text { 6th } \\
\text { cycle }\end{array}$ \\
\hline S-2 & 74 & 74 & 72.5 & 71.75 & 71 & 70 \\
S-3 & 75 & 74 & 73 & 73 & 72.5 & 72 \\
\hline
\end{tabular}

Thermodynamics plays a significant role in understanding the conversion of energy into mass and vice versa. Thermodynamic studies provide vital information on internal energy variations, as well as the spontaneity and heat change of the adsorption process $[45,46]$. The estimation of parameters standard free energy change $\left(\Delta G^{\circ}\right)$, the standard enthalpy change $\left(\Delta H^{\circ}\right)$, and the standard entropy change $\left(\Delta S^{\circ}\right)$ is presented in Supp.3. Pirimicarb separation was better at $75^{\circ} \mathrm{C}$, confirming the robustness of the adsorbateadsorbent interaction at high temperatures. The weak compactness of the system, which is the core aspect of boosting the randomness at the solid-solution interface, is due to the $\pi$-anionic and cationic between pirimicarb and ILs. As a result, the extraction of pirimicarb is enhanced at high temperatures, as evidenced by $\Delta G^{\circ}$ values obtained at various temperature ranges. Negative $\Delta G^{\circ}$ values indicated the likelihood of extraction and the spontaneous nature of the separation process at a given temperature. The decreasing value of $\Delta G^{\circ}$ as temperature rises indicates an increase in the degree of pirimicarb extraction feasibility. Physical adsorption enthalpy $\left(\Delta H^{\circ}\right)$ varies from -20 to $40 \mathrm{~kJ} \mathrm{~mol}^{-1}$, whereas chemical adsorption enthalpy $\left(\Delta H^{\circ}\right)$ varies from -80 to $400 \mathrm{~kJ} \mathrm{~mol}^{-1}$. A negative charge on $\mathrm{H}$ in this study indicates that the extraction process is physisorption and endothermic in nature. During the separation process, the increased randomness leads to an increase in the degree of freedom at the IL-pirimicarb solution interface.

The positive $\Delta S^{\circ}$ could be reorganized from the point where sodium dehydration causes a large entropy boost in their transfer from water to the ILs [47]. Furthermore, all of the $\Delta H^{\circ}$ values in Table 4 are less than $40 \mathrm{~kJ} \mathrm{~mol}^{-1}$, indicating that the pirimicarb extraction by imidazolium-based ILs is consistent with the physical adsorption process [48]. Furthermore, in this system, all of the $\Delta S^{\circ}$ values were positive, indicating that randomness was boosted on the solidliquid interface during the extraction process. The possible cause was that the water molecules on the surface of ILs were replaced by pirimicarb, which has a larger molecule volume [37], increasing the system's entropy value. As a result, increasing the temperature to $75^{\circ} \mathrm{C}$ helps the synthesized ILs extract pirimicarb.

3.4. Extraction Mechanism. The pseudo-first-order model and intraparticle diffusion model fit the experimental data well. The imidazolium-based ILs enable the separation of pirimicarb from an aqueous solution, according to the pseudo-first-order model. The capability of imidazoliumbased ILs to extract pirimicarb is governed by two significant interactions. In the structure of pirimicarb, the first is the formation of $\mathrm{H}$-bonds, in which the bromide ions act as an electron donor to $\mathrm{N}$. The Br-'s high electronegativity promotes $\mathrm{H}$-bonding, which is important in the separation process. The second driving force for the separation of pirimicarb by imidazolium-based ILs is the $\pi-\pi$ conjugation between the modified imidazolium ring and the benzene ring of pirimicarb [11].

The role of aromatic moieties in the strengthening interaction of ILs with the ring of pirimicarb can be seen in their ${ }^{1} \mathrm{H}$ NMR spectrum, which is surprising. This is because aromatic compounds attracted to cationic imidazolium rings modified with saturated substituents such as alkyl more efficiently than unmodified counterparts [49]. The $\pi-\pi$ interaction of pirimicarb's aromatic benzene ring with aromatic moieties of S-3, as well as the $\mathrm{H}$-bonding of $\mathrm{Br}^{-}$with the carboxylic group of pirimicarb, is illustrated in Figure 8(a).

In addition, the solid-liquid extraction of pirimicarbimidazolium-based ILs followed the intraparticle diffusion model. The transfer of pirimicarb ions in this mechanism is usually classified as external diffusion (film diffusion), internal diffusion (intraparticle diffusion), or both (film and intraparticle diffusion). Three sequential steps occur during the extraction of pirimicarb onto imidazoliumbased ILs, as shown in Figure 8(b).

3.5. Recycling Performance of the Adsorbent. From an economic point of view, the ability to regenerate the IL for reuse is one of the important factors for industrial applications because regeneration will reduce reagent costs in removing pollutants.

In previous researches, toluene was used as an extracting solvent for pollutants which is very toxic so the desorption study was conducted after having many trials with chloroform or ethanol [50]. Our results showed a very encouraging potential of ILs for removal of pirimicarb even after six repeated cycles using ethanol.

After complete removal of pirimicarb from orchard wastewater using functionalized ILs, the regeneration capability of sorbents was investigated for repeated adsorption efficiency under the same conditions as those used for virgin adsorbents. After six (6) adsorption/desorption cycles (as shown in Table 5), the performance of the regenerated S-3 showed retention of $>70 \%$ efficiencies, indicating that S-3 is an excellent reusable adsorbent [51]. Moreover, it was worth mentioning that as the desorption experiment before regeneration was performed using ethanol as extracting solvent [52], functionalized ILs are sustainable to use. The results are quite similar as reported in published literature.

\section{Conclusions}

For the first time, pirimicarb can be extracted from orchard wastewater using various imidazolium-based ionic liquids (S-1 to S-4). FTIR, SEM, XRD, TGA, BET, and ${ }^{1} \mathrm{H}$ NMR spectroscopy confirmed that the fabricated imidazolium ILs were successfully synthesized. According to an XRD analysis, imidazolium-based ILs are crystalline, with an average particle size of $>100 \mathrm{~nm}$. The results of SEM were used to investigate the well-organized, needle-shaped surface 
morphology of ILs with a high surface area to volume ratio. ILs that have been synthesized have the ability to extract and separate. In general, the fabricated ILs were more efficient at removing pirimicarb in the following order: S-3 $>$ S-2 $>$ S-4 $>$ S-1. The ILs have good regeneration capability even after six (6) cycles, described by the pseudo-first-order and Langmuir models. The adsorption process is also controlled by the intraparticle diffusion. According to the thermodynamic parameters, pirimicarb extraction is spontaneous and endothermic. Our findings are very promising for the practical application of the synthesized ILs for the removal of pirimicarb from real orchard wastewater and grant a new perspective on the utilization of this approach in water treatment.

\section{Data Availability}

The generated and analyzed data during the current study is supplied in this manuscript and is readily available from the corresponding authors upon reasonable request.

\section{Conflicts of Interest}

The authors declare that there is no conflict of interest regarding the publication of this article.

\section{Authors' Contributions}

Sana Zulfiqar is responsible for conceptualization, methodology, investigation, validation, formal analysis, visualization, data curation, resources, and supervision. Uzaira Rafique is responsible for methodology, investigation, visualization, and resources. M. Javed Akhtar is responsible for methodology, investigation, visualization, and resources. Hesham Hamad is responsible for conceptualization, methodology, investigation, validation, formal analysis, visualization, data curation, writing, editing, reviewing, supervision, and project administration.

\section{Acknowledgments}

The authors are deeply grateful to Fatima Jinnah Women University and Pakistan Institute of Nuclear Science and Technology in Pakistan and the City of Scientific Research and Technological Applications (SRTA-City) and the Alexandria University in Egypt. H. Hamad also acknowledges the Faculty of Science, Warsaw University, for the computer services.

\section{Supplementary Materials}

Supplementary 1. Characterization of ILs. Supplementary 2. Adsorption experiments. Supplementary 3. Estimation of thermodynamic parameters. Figure S1: study of area, Punjab, Jhelum District, Pakistan. Table S1: chemical structure and physicochemical properties of pirimicarb. Table S2: kinetic and equilibrium isotherm models utilized to describe pirimicarb adsorption process onto prepared ionic liquids. Table S3: isotherm parameters of pirimicarb adsorption onto prepared imidazolium-based ILs. (Supplementary Materials)

\section{References}

[1] J. Fenoll, I. Garrido, P. Hellín, P. Flores, N. Vela, and S. Navarro, "Photocatalytic oxidation of pirimicarb in aqueous slurries containing binary and ternary oxides of zinc and titanium," J Photochem Photobiol A Chem, vol. 298, pp. 24-32, 2015.

[2] C.-C. Chen, H.-J. Fan, J. Shaya et al., "Accelerated ZnMoO4photocatalytic degradation of pirimicarb under UV light mediated by peroxymonosulfate," Applied Organometallic Chemistry, vol. 33, p. 5113, 2019.

[3] Q. J. Luo, Y. X. Li, M. Q. Zhang, P. Qiu, and Y. H. Deng, “A highly sensitive, dual-signal assay based on rhodamine B covered silver nanoparticles for carbamate pesticides," Chin Chem Lett, vol. 28, no. 2, pp. 345-349, 2017.

[4] Y. Wang, B. Yang, P. Zhang et al., "Heterogeneous reactions of pirimiphos-methyl and pirimicarb with $\mathrm{NO}_{3}$ radicals," Journal of Physical Chemistry A, vol. 116, pp. 10802-10809, 2012.

[5] G. S. Natale, J. Vera Candioti, C. Ruiz de Arcaute, S. Soloneski, M. L. Larramendy, and A. E. Ronco, "Lethal and sublethal effects of the pirimicarb-based formulation Aficida ${ }^{\oplus}$ on _Boana pulchella_ (Dum eril and Bibron, 1841) tadpoles (Anura, Hylidae)," Ecotoxicology and Environmental Safety, vol. 147, pp. 471-479, 2018.

[6] J. A. Turner, the Pesticide Manual, 15th ed., C. D. Tomlin, Ed., British Crop Protection Council: Surrey, 2009.

[7] T. Shalaby, H. Hamad, E. Ibrahim, O. Mahmoud, and A. AlOufy, "Electrospun nanofibers hybrid composites membranes for highly efficient antibacterial activity," Ecotoxicology and Environmental Safety, vol. 162, pp. 354-364, 2018.

[8] D. G. Bassyouni, H. A. Hamad, E.-S. Z. El-Ashtoukhy, N. K. Amin, and M. M. Abd El-Latif, "Comparative performance of anodic oxidation and electrocoagulation as clean processes for electrocatalytic degradation of diazo dye Acid Brown 14 in aqueous medium," Journal of Hazardous Materials, vol. 335, pp. 178-187, 2017.

[9] W. A. Sadik, A. M. El-Demerdash, A. W. Nashed, A. A. Mostafa, and H. A. Hamad, "Highly efficient photocatalytic performance of $\mathrm{Cu}_{2}$ [email protected $]_{2}$ nanocomposite: influence of various inorganic oxidants and inorganic anions," Journal of Materials Research and Technology, vol. 8, no. 6, pp. 54055414, 2019.

[10] Z. Jia, S. Hao, and Z. Liu, "Synthesis of $\mathrm{BaSO}_{4}$ nanoparticles with a membrane reactor: parameter effects on membrane fouling," Journal of Membrane Science, vol. 543, pp. 277-281, 2017.

[11] A. A. Hamad, M. S. Hassouna, T. I. Shalaby, M. F. Elkady, M. A. A. Elkawi, and H. A. Hamad, "Electrospun cellulose acetate nanofiber incorporated with hydroxyapatite for removal of heavy metals," International Journal of Biological Macromolecules, vol. 151, pp. 1299-1313, 2020.

[12] N. Nasrollahi, S. Aber, V. Vatanpour, and N. M. Mahmoodi, "Development of hydrophilic microporous PES ultrafiltration membrane containing $\mathrm{CuO}$ nanoparticles with improved antifouling and separation performance," Materials Chemistry and Physics, vol. 222, pp. 338-350, 2019.

[13] N. M. Mahmoodi, M. Oveisi, A. Taghizadeh, and M. Taghizadeh, "Novel magnetic amine functionalized carbon nanotube/metal-organic framework nanocomposites: from green ultrasound-assisted synthesis to detailed selective pollutant removal modelling from binary systems," Journal of Hazardous Materials, vol. 368, pp. 746-759, 2019. 
[14] P. Wilczewska, A. Bielicka-Giełdońa, A. F. Borzyszkowsk, T. Klimczuk, and E. M. Siedlecka, "Photocatalytic activity of solvothermal prepared $\mathrm{BiOClBr}$ with imidazolium ionic liquids as a halogen sources in cytostatic drugs removal," Journal of Photochemistry and Photobiology A: Chemistry, vol. 382, article ???, 2019.

[15] M. Zhao, L. Wei, Y. Zheng, M. Liu, J. Wang, and Y. Qiu, "Structural effect of imidazolium-type ionic liquid adsorption to montmorillonite," Science of the Total Environment, vol. 666, pp. 858-864, 2019.

[16] R. Zarrougui, R. Mdimagh, and N. Raouaf, "Highly efficient extraction and selective separation of uranium (VI) from transition metals using new class of undiluted ionic liquids based on H-phosphonate anions," Journal of Hazardous Materials, vol. 342, pp. 464-476, 2018.

[17] R. A. El-Nagar, M. Nessim, A. Abd El-Wahab, R. Ibrahim, and S. Faramawy, "Investigating the efficiency of newly prepared imidazolium ionic liquids for carbon dioxide removal from natural gas," Journal of Molecular Liquids, vol. 237, pp. 484489, 2017.

[18] N. Sidek, N. S. A. Manan, and S. Mohamad, "Efficient removal of phenolic compounds from model oil using benzyl imidazolium-based ionic liquids," Journal of Molecular Liquids, vol. 240, pp. 794-802, 2017.

[19] S. Zulfiqar, U. Rafique, and M. J. Akhtar, "Removal of pirimicarb from agricultural waste water using cellulose acetatemodified ionic liquid membrane," Environmental Science and Pollution Research, vol. 26, no. 16, pp. 15795-15802, 2019.

[20] J. Maszkowska, E. Synak, A. Fabiańska et al., "Preliminary study on suitability of ionic liquids as potential passivesampling media of polyaromatic-hydrocarbon (PAH) analyses in water," Analytical and Bioanalytical Chemistry, vol. 407, no. 12, pp. 3531-3536, 2015.

[21] B. Ekka, R. S. Dhaka, R. K. Patel, and P. Dash, "Fluoride removal in waters using ionic liquid-functionalized alumina as a novel adsorbent," Journal of Cleaner Production, vol. 151, pp. 303-318, 2017.

[22] A. Hamadi, N. Yeddou-Mezenner, A. Lounis, R. M. Ali, and H. Hamad, "Upgrading of agro-industrial green biomass residues from chocolate industry for adsorption process: diffusion and mechanistic insights," Journal of Food Science and Technology, vol. 58, no. 3, pp. 1081-1092, 2021.

[23] W. Guo, Y. Hou, W. Wu, S. Ren, S. Tian, and K. N. Marsh, "Separation of phenol from model oils with quaternary ammonium saltsvia forming deep eutectic solvents," Green Chemistry, vol. 15, no. 1, pp. 226-229, 2013.

[24] R. Cooper, A. M. Zolot, J. A. Boatz, D. P. Sporleder, and J. A. Stearns, "IR and UV spectroscopy of vapor-phase jet-cooled ionic liquid $\mathrm{EMIM}^{+} \mathrm{Tf}_{2} \mathrm{~N}^{-}$: ion pair structure and photodissociation dynamics," Journal of Physical Chemistry A, vol. 117, pp. 12419-12428, 2013.

[25] M. Matandabuzo and P. A. Ajibade, "Synthesis and surface functionalization of multi-walled carbon nanotubes with imidazolium and pyridinium-based ionic liquids: thermal stability, dispersibility and hydrophobicity characteristics," Journal of Molecular Liquids, vol. 268, pp. 284-293, 2018.

[26] Y. Lin, F. Wang, Z. Zhang, J. Yang, and Y. Wei, "Polymer-supported ionic liquids: synthesis, characterization and application in fuel desulfurization,” Fuel, vol. 116, pp. 273-280, 2014.

[27] A. Chowdhury and S. T. Thynell, "Confined rapid thermolysis/ FTIR/ToF studies of imidazolium-based ionic liquids," Thermochimica Acta, vol. 443, pp. 159-172, 2006.
[28] T. Erdmenger, J. Vitz, F. Wiesbrock, and U. S. Schubert, "Influence of different branched alkyl side chains on the properties of imidazolium-based ionic liquids," Journal of Materials Chemistry A, vol. 18, no. 43, pp. 5267-5273, 2008.

[29] N. M. Mahmoodi and J. Abdi, "Nanoporous metal-organic framework (MOF-199): synthesis, characterization and photocatalytic degradation of Basic Blue41," Microchemical Journal, vol. 144, pp. 436-442, 2019.

[30] H. Hamad, E. Bailón-García, S. Morales-Torres, F. CarrascoMarín, A. F. Pérez-Cadenas, and F. J. Maldonado-Hódar, "Functionalized cellulose for the controlled synthesis of novel carbon-Ti nanocomposites: physicochemical and photocatalytic properties," Nanomaterials, vol. 10, p. 729, 2020.

[31] A. P. Abbott, T. J. Bell, S. Handa, and B. Stoddart, "O-Acetylation of cellulose and monosaccharides using a zinc based ionic liquid," Green Chemistry, vol. 7, no. 10, pp. 705-707, 2005.

[32] D. Yuan, D. He, S. Xu et al., "Imidazolium-based ionic liquids as novel organic SDA to synthesize high-silica Y zeolite," Microporous and Mesoporous Materials, vol. 204, pp. 1-7, 2015.

[33] K. Noack, P. S. Schulz, N. Paape, J. Kiefer, P. Wasserscheid, and A. Leipertz, "The role of the $\mathrm{C} 2$ position in interionic interactions of imidazolium based ionic liquids: a vibrational and NMR spectroscopic study," Physical Chemistry Chemical Physics, vol. 12, no. 42, pp. 14153-14161, 2010.

[34] J. Dai, D. Majhi, B. B. Kharkov, and S. V. Dvinskikh, "NMR spectroscopic study of orientational order in imidazoliumbased ionic liquid crystals," Crystals, vol. 9, p. 495, 2019.

[35] R. Hayes, G. G. Warr, and R. Atkin, "Structure and nanostructure in ionic liquids," Chemical Reviews, vol. 115, no. 13, pp. 6357-6426, 2015.

[36] Y. Li, L. Wei, W. Zhang, Z. Dong, and Y. Qiu, "Counteraniondependent sorption of imidazolium- and benzimidazoliumbased ionic liquids by soot," Chemosphere, vol. 202, pp. 264271, 2018.

[37] P. A. Hunt, C. R. Ashworth, and R. P. Matthews, "Hydrogen bonding in ionic liquids," Chemical Society Reviews, vol. 44, pp. 1257-1288, 2015.

[38] J. Zhang, S. S. Liu, J. Zhang, L. T. Qin, and H. P. Deng, "Two novel indices for quantitatively characterizing the toxicity interaction between ionic liquid and carbamate pesticides," Journal of Hazardous Materials, vol. 239-240, pp. 102-109, 2012.

[39] E. M. El-Sayed, H. A. Hamad, and R. M. Ali, "Journey from ceramic waste to highly efficient toxic dye adsorption from aqueous solutions via one-pot synthesis of $\mathrm{CaSO}_{4}$ rod-shape with silica," Journal of Materials Research and Technology, vol. 9, pp. 16051-16063, 2020.

[40] L. He, W. Cui, Y. Wang et al., "Polymeric ionic liquid based on magnetic materials fabricated through layer- by-layer assembly as adsorbents for extraction of pesticides," Journal of Chromatography A, vol. 1522, pp. 9-15, 2017.

[41] H. Shokry, M. Elkady, and H. Hamad, "Nano activated carbon from industrial mine coal as adsorbents for removal of dye from simulated textile wastewater: operational parameters and mechanism study," Journal of Materials Research and Technology, vol. 8, pp. 4477-4488, 2019.

[42] F. C. Wu, R. L. Tseng, and R. S. Juang, "Initial behavior of intraparticle diffusion model used in the description of adsorption kinetics," Chemical Engineering Journal, vol. 153, no. 1-3, pp. 1-8, 2009. 
[43] M. F. F. Sze and G. McKay, "An adsorption diffusion model for removal of para-chlorophenol by activated carbon derived from bituminous coal," Environmental Pollution, vol. 158, no. 5, pp. 1669-1674, 2010.

[44] M. Elkady, H. Shokry, and H. Hamad, "Effect of superparamagnetic nanoparticles on the physicochemical properties of nano hydroxyapatite for groundwater treatment: adsorption mechanism of Fe(ii) and $\mathrm{Mn}(\mathrm{ii}), "$ RSC Advances, vol. 6, no. 85, pp. 82244-82259, 2016.

[45] S. Zulfiqar, U. Rafique, M. J. Akhtar, A. Hussain, and S. Mansab, "Thermodynamic and kinetics study of phosphonium-based cellulose acetate supported ionic liquid membrane: wastewater treatment," Desalination and Water Treatment, vol. 133, pp. 20-27, 2018.

[46] M. Doğan, H. Abak, and M. Alkan, "Adsorption of methylene blue onto hazelnut shell: kinetics, mechanism and activation parameters," Journal of Hazardous Materials, vol. 164, no. 1, pp. 172-181, 2009.

[47] Z. Wu, H. Zhong, X. Yuan et al., "Adsorptive removal of methylene blue by rhamnolipid-functionalized graphene oxide from wastewater," Water Research, vol. 67, pp. 330-344, 2014.

[48] M. Cobas, M. A. Sanromán, and M. Pazos, “Box-Behnken methodology for Cr (VI) and leather dyes removal by an eco-friendly biosorbent: F. vesiculosus," Bioresource Technology, vol. 160, pp. 166-174, 2014.

[49] A. Dimitrijević, L. Ignjatović, A. Tot et al., "Simultaneous extraction of pesticides of different polarity applying aqueous biphasic systems based on ionic liquids," Journal of Molecular Liquids, vol. 243, pp. 646-653, 2017.

[50] Q. Wu, G. Zhao, C. Feng, C. Wang, and Z. Wang, "Preparation of a graphene-based magnetic nanocomposite for the extraction of carbamate pesticides from environmental water samples," Journal of Chromatography A, vol. 1218, no. 44, pp. 7936-7942, 2011.

[51] C. W. G. Baojiao and S. H. I. Xuejun, "Preparation of functional grafted particles $\mathrm{PSSS} / \mathrm{SiO}_{2}$ and their adsorption character towards heterocyclic pesticides containing nitrogen atom," Environmental Chemistry, vol. 3, 2013.

[52] R. Rojas, E. Vanderlinden, J. Morillo, J. Usero, and H. El Bakouri, "Characterization of sorption processes for the development of low-cost pesticide decontamination techniques," Science of the Total Environment, vol. 488-489, pp. 124-135, 2014. 